\title{
Exercise SBP response and incident depressive symptoms: The Maastricht Study
}

Citation for published version (APA):

Zhou, T. L., Kroon, A. A., Henry, R. M. A., Koster, A., Dagnelie, P. C., Bosma, H., van Greevenbroek, M. M. J., van der Kallen, C. J. H., Schalkwijk, C. G., Wesselius, A., Reesink, K. D., Köhler, S., Schram, M. T., Stehouwer, C. D. A., \& van Sloten, T. T. (2021). Exercise SBP response and incident depressive symptoms: The Maastricht Study. Journal of Hypertension, 39(3), 494-502. https://doi.org/10.1097/HJH.0000000000002657

Document status and date:

Published: 01/03/2021

DOI:

10.1097/HJH.0000000000002657

Document Version:

Publisher's PDF, also known as Version of record

Document license:

Taverne

Please check the document version of this publication:

- A submitted manuscript is the version of the article upon submission and before peer-review. There can be important differences between the submitted version and the official published version of record.

People interested in the research are advised to contact the author for the final version of the publication, or visit the DOI to the publisher's website.

- The final author version and the galley proof are versions of the publication after peer review.

- The final published version features the final layout of the paper including the volume, issue and page numbers.

Link to publication

\footnotetext{
General rights rights.

- You may freely distribute the URL identifying the publication in the public portal. please follow below link for the End User Agreement:

www.umlib.nl/taverne-license

Take down policy

If you believe that this document breaches copyright please contact us at:

repository@maastrichtuniversity.nl

providing details and we will investigate your claim.
}

Copyright and moral rights for the publications made accessible in the public portal are retained by the authors and/or other copyright owners and it is a condition of accessing publications that users recognise and abide by the legal requirements associated with these

- Users may download and print one copy of any publication from the public portal for the purpose of private study or research.

- You may not further distribute the material or use it for any profit-making activity or commercial gain

If the publication is distributed under the terms of Article $25 \mathrm{fa}$ of the Dutch Copyright Act, indicated by the "Taverne" license above, 


\title{
Original Article
}

\section{Exercise SBP response and incident depressive symptoms: The Maastricht Study}

\author{
Tan Lai Zhou ${ }^{a, b}$, Abraham A. Kroon ${ }^{a, b}$, Ronald M.A. Henry ${ }^{a, b, c}$, Annemarie Koster ${ }^{\text {d,e }}$ \\ Pieter C. Dagnelie ${ }^{b, f}$, Hans Bosma ${ }^{d, e}$, Marleen M.J. van Greevenbroek ${ }^{a, b}$ \\ Carla J.H. van der Kallen ${ }^{a, b}$, Casper G. Schalkwijk ${ }^{a, b}$, Anke Wesselius ${ }^{\text {g, }}$ \\ Koen D. Reesink ${ }^{b, i}$, Sebastian Köhler ${ }^{j, k}$, Miranda T. Schram ${ }^{a, b, c}$ \\ Coen D.A. Stehouwer ${ }^{a, b}$, and Thomas T. van Sloten ${ }^{a, b, l, m}$
}

Objective : An exaggerated exercise SBP, which is potentially modifiable, may be associated with incident depressive symptoms via an increased pulsatile pressure load on the brain. However, the association between exaggerated exercise SBP and incident depressive symptoms is unknown. Therefore, we examined whether exaggerated exercise SBP is associated with a higher risk of depressive symptoms over time.

Methods: We used longitudinal data from the population-based Maastricht Study, with only individuals free of depressive symptoms at baseline included ( $n=2121 ; 51.3 \%$ men; age $59.5 \pm 8.5$ years). Exercise SBP was measured at baseline with a submaximal exercise cycle test. We calculated a composite score of exercise SBP based on four standardized exercise SBP measures: SBP at moderate workload, SBP at peak exercise, SBP change per minute during exercise and SBP 4 min after exercise. Clinically relevant depressive symptoms were determined annually at follow-up and defined as a Patient Health Questionnaire score of at least 10.

Results : After a mean follow-up of 3.9 years, 175 participants $(8.3 \%)$ had incident clinically relevant depressive symptoms. A 1 SD higher exercise SBP composite score was associated with a higher incidence of clinically relevant depressive symptoms [hazard ratio: 1.27 (95\% confidence interval: 1.04-1.54)]. Results were adjusted for age, sex, education level, glucose metabolism status, lifestyle, cardiovascular risk factors, resting SBP and cardiorespiratory fitness.

Conclusion : A higher exercise SBP response is associated with a higher incidence of clinically relevant depressive symptoms.

Keywords: blood pressure, depression, exercise, prognosis, screening

Abbreviation: PHQ-9, Patient Health Questionnaire-9

\section{INTRODUGTION}

$\mathrm{D}$ epression is a leading cause of disability among older individuals with cardiovascular disease [1]. The prevalence of depression is two to three times higher among patients with cardiovascular disease than in the general population [2], and depression is associated with lower quality of life and higher mortality in these individuals [3]. Prior studies have provided strong evidence for a bidirectional association between cardiovascular disease and depression [4,5]. The mechanisms underlying this association are multifactorial. Among these, vascular dysfunction has received prominent attention as a potentially modifiable shared mechanism. An exaggerated exercise blood pressure (BP) response, a marker of vascular dysfunction [6], may be such a mechanism.

It has been suggested that cerebrovascular dysfunction and damage in regions involved in mood regulation contributes to the development of depression (vascular depression hypothesis) [7]. In accordance, studies have shown that several cardiovascular risk factors (e.g. diabetes [8], physical inactivity [9], unhealthy dietary habits [10] and chronic kidney disease [11]) and subclinical markers of vascular disease (e.g. arterial stiffness [12], plasma biomarkers of endothelial dysfunction [13] and MRI features of cerebral small vessel disease in frontal and deep brain regions [14]) are associated with a higher risk of depression. These associations were independent of a large set of potential confounders, including socioeconomic status, comorbid anxiety or other chronic illnesses.

\section{Journal of Hypertension 2021, 39:494-502}

${ }^{a}$ Department of Internal Medicine, Maastricht University Medical Centre+, ${ }^{b}$ CardioCardiovascular Research Institute Maastricht (CARIM), Maastricht University, ' ${ }^{C}$ Heart and Vascular Centre, Maastricht University Medical Centre+, ${ }^{\mathrm{d} C A P H R I}$ Care and Public Health Research Institute, Maastricht University, ${ }^{\circ}$ Maastricht University, Department of Social Medicine, Maastricht University, ${ }^{\mathrm{D}}$ Department of Epidemiology, Maastricht University, ${ }^{9}$ Department of Complex Genetics, Maastricht University, ${ }^{\text {NUTRIM }}$ School for Nutrition and Translational Research in Metabolism, 'Department of Biomedical Engineering, Maastricht University, 'Department of Psychiatry and Neuropsychology, Alzheimer Centre Limburg, Maastricht University Medical Centre+. ${ }^{k}$ MHeNs School for Mental Health and Neuroscience, Maastricht University, Maastricht, The Netherlands, 'Université Paris Descartes, Sorbonne Paris Cité, Faculté de Médecine and ${ }^{m}$ Department of Epidemiology and Department of Arterial Mechanics, INSERM, UMR-S970, Paris Cardiovascular Research Centre, Paris, France

Correspondence to Thomas T. van Sloten, Department of Internal Medicine, Maastricht University Medical Centre+, P. Debyelaan 25, PO Box 5800, 6202 AZ Maastricht, The Netherlands. Tel: +31 6212145 90; fax: +31 4338750 06; e-mail: t.vansloten@maastrichtuniversity.n

Received 6 May 2020 Revised 2 August 2020 Accepted 23 August 2020

J Hypertens 39:494-502 Copyright (C) 2020 Wolters Kluwer Health, Inc. All rights reserved.

DOI:10.1097/HJH.0000000000002657 
However, data on the association between hypertension, defined by use of mean $\mathrm{BP}$, and incident depression are inconsistent. One study found an association between hypertension and incident depression [15], whereas others did not [16-18]. Mean BP may, however, not fully capture the pulsatile aspect of BP [6]. The low impedance circulation of the brain is particularly susceptible to an increased pulsatile load, as this increased may penetrate deeply into the vasculature of the brain [19]. An exaggerated exercise SBP, which is potentially modifiable [20], may be a better reflection of an increased pulsatile load exerted by BP $[6,21,22]$. Previous studies have shown associations between exercise BP and lower total brain volume [23] and higher white matter hyperintensity volume [24]. However, the association between exercise BP and depression is unknown.

We therefore sought to investigate the longitudinal association between exercise SBP and risk of depressive symptoms over time in a large population-based study.

\section{METHODS}

\section{The Maastricht Study}

We used data from the Maastricht Study, an observational prospective population-based cohort study. The rationale and methodology have been described previously [25]. In brief, the study focuses on the cause, pathophysiology, complications and comorbidities of type 2 diabetes mellitus and is characterized by an extensive phenotyping approach. Eligible for participation were all individuals aged between 40 and 75 years and living in the southern part of the Netherlands. Participants were recruited through mass media campaigns and from the municipal registries and the regional Diabetes Patient Registry via mailings. Recruitment was stratified according to known type 2 diabetes status, with an oversampling of individuals with type 2 diabetes for reasons of efficiency. The present report includes data from 3451 participants who completed the baseline survey between November 2010 and September 2013, and received annual follow-up questionnaires for up to 4 years. The baseline examinations of each participant were performed within a time window of 3 months. The study has been approved by the institutional medical ethical committee (NL31329.068.10) and the Minister of Health, Welfare and Sports of the Netherlands (Permit 131088105234-PG). All participants gave written informed consent. Data are available from the Maastricht Study for any researcher who meets the criteria for access to confidential data, and the corresponding author may be contacted to request data.

\section{Submaximal exercise test and exercise blood pressure}

A graded, submaximal limited exercise test was performed on a cycle ergometer system (CASE v6.6 in combination with e-bike; GE Healthcare, Milwaukee, Wisconsin, USA), as described previously [26]. Individuals were excluded from participation in the test if they had experienced cardiovascular complications in the preceding 3 months, had an abnormal resting ECG, had a resting SBP at least 180 and/or DBP at least $110 \mathrm{mmHg}$, or an implantable cardioverter defibrillator or pacemaker. Eligible participants were fitted with a BP cuff on the upper left arm (Tango+; SunTech Medical, Inc., Morrisville, North Carolina, USA) and chest electrodes to provide a continuous 12-lead ECG recording [27]. Participants were instructed to cycle at a cadence of 60-70 rotations per minute during a short familiarization period without any external workload. For the first exercise stage, external workload was set at $25 \mathrm{~W}$. Every consecutive stage (i.e. every $2 \mathrm{~min}$ ) external workload was increased by $25 \mathrm{~W}$. At the end of each stage, heart rate (HR) and $\mathrm{BP}$ were measured and participants were asked to provide a rating of perceived exertion on the 15-point Borg-scale; an interval scale ranging from 6 (no exertion at all) to 20 (maximal exertion). The exercise test was considered 'completed' and stopped when the HR reached at least $85 \%$ of the estimated maximum HR (i.e. 220-age), when a rating of perceived exertion of at least 17 was scored by participants, or by the end of stage 7 (workload $175 \mathrm{~W}$ ). The test could also be terminated on medical grounds or when participants were unwilling to continue. After the test, participants remained seated for at least $4 \mathrm{~min}$. BP was measured at rest before the start of the exercise test, at the end of each stage, at peak exercise (i.e. when the test was stopped) and at $4 \mathrm{~min}$ after exercise.

For the current study, we considered the following exercise SBP variables, based on previous studies [21,28]: SBP at moderate workload (stage 2), SBP at peak exercise, SBP change per minute (calculated from start to peak exercise using individual linear regression lines) and SBP at $4 \mathrm{~min}$ after exercise. These exercise SBP variables have been associated with a higher cardiovascular disease risk independently of resting SBP $[21,28]$.

\section{Depressive symptoms}

Depressive symptoms were assessed at baseline and each year at follow-up with a validated Dutch version of the 9item Patient Health Questionnaire (PHQ-9) [29], as described previously [25]. The PHQ-9 is a self-administered questionnaire and is based on the Diagnostic and Statistical Manual of Mental Disorders 4th edition criteria for a major depressive episode. It comprises nine items rated on a fourpoint scale, ranging from 0 (not at all) to 3 (nearly every day). Response options are used to calculate a continuous total depressive symptom score ranging from 0 (no symptoms) to 27 (all symptoms present nearly every day). A predefined cutoff score of at least 10 was used to indicate clinically relevant depressive symptoms [29].

\section{Covariates}

Sociodemographic variables included age, sex, partner status and socioeconomic status [education level (low, intermediate or high), occupational status and income]. Lifestyle variables included alcohol consumption (none, low or high), smoking status (never, former or current) and amount of moderate-to-vigorous physical activity. Cardiovascular variables included glucose metabolism status (normal glucose metabolism, prediabetes or diabetes), BMI, prior cardiovascular disease, estimated glomerular filtration rate, lipid profile, use of lipid-modifying and 
(classes of) antihypertensive medication, cardiorespiratory fitness (maximum power output during the submaximal exercise test adjusted for body mass), aortic stiffness (as determined by carotid-to-femoral pulse wave velocity), markers of low-grade inflammation (i.e. C-reactive protein, serum amyloid A, TNF- $\alpha$, IL-6 and IL-8), markers of endothelial dysfunction (i.e. soluble intercellular adhesion molecule-1, soluble vascular adhesion molecule-1, soluble Eselectin and von Willebrand factor) [30] and 24-h BP. Further details and definitions of potential confounders are provided in the Supplemental Methods, http://links. lww.com/HJH/B460.

\section{Analytical sample}

Of the 3451 participants, 293 had missing data on the PHQ-9 score or use of antidepressant medication at baseline, 192 on the PHQ-9 at all follow-up examinations, 703 on the exercise test and 745 on any covariates (numbers not mutually exclusive), and these individuals were excluded. In addition, $81(3.7 \%)$ had baseline clinically relevant depressive symptoms (PHQ-9 score $\geq 10$ ) at baseline and were excluded. The final study population therefore consisted of 2121 participants (Fig. 1). Participants excluded compared with those included in the analyses were older, more often had no partner and had a worse cardiovascular risk profile (Supplemental Table S1, http://links.lww.com/ $\mathrm{HJH} / \mathrm{B} 460)$.

\section{Statistical analysis}

We calculated a composite score of exercise SBP by standardizing and averaging the four exercise SBP variables. This score was used as the main determinant in all analyses. A composite score reduces the biological variability of each individual measure [31] and reduces the number of statistical tests.

We used Cox proportional hazards models to estimate hazard ratios for the association between the exercise SBP composite score and incident clinically relevant depressive symptoms (PHQ-9 score $\geq 10$ ) with time-in-study as the time scale. Participants were censored at the first occurrence of incident clinically relevant depressive symptoms or at the time of the last examination in those without incident clinically relevant symptoms.

We adjusted all analyses for the following potential confounders based on the previous literature [32-35]: age, sex, glucose metabolism status and education level (model 1), and additionally for partner status, alcohol consumption, smoking status, BMI and prior cardiovascular disease (model 2), and estimated glomerular filtration rate, total-to-HDL cholesterol ratio, resting SBP and use of lipidmodifying and antihypertensive medication (with the individual antihypertensive classes separately) (model 3), and cardiorespiratory fitness (model 4), and baseline PHQ-9 scores (model 5).

We tested for clinically relevant interactions, that is, exercise $\mathrm{SBP} \times$ sex, exercise $\mathrm{SBP} \times$ age and exercise $\times(-$ (pre)diabetes, because age, sex and (pre)diabetes might modify the association between vascular dysfunction and depression [36-38].

We performed several additional analyses: first, we used resting office SBP and 24-h SBP as the determinant instead of the exercise SBP composite score; second, we used the exercise DBP composite score as the determinant instead of the exercise SBP composite score; third, we repeated the main analyses with each of the four baseline exercise SBP variables as the determinants (i.e. SBP at moderate workload, SBP at peak exercise, SBP change per

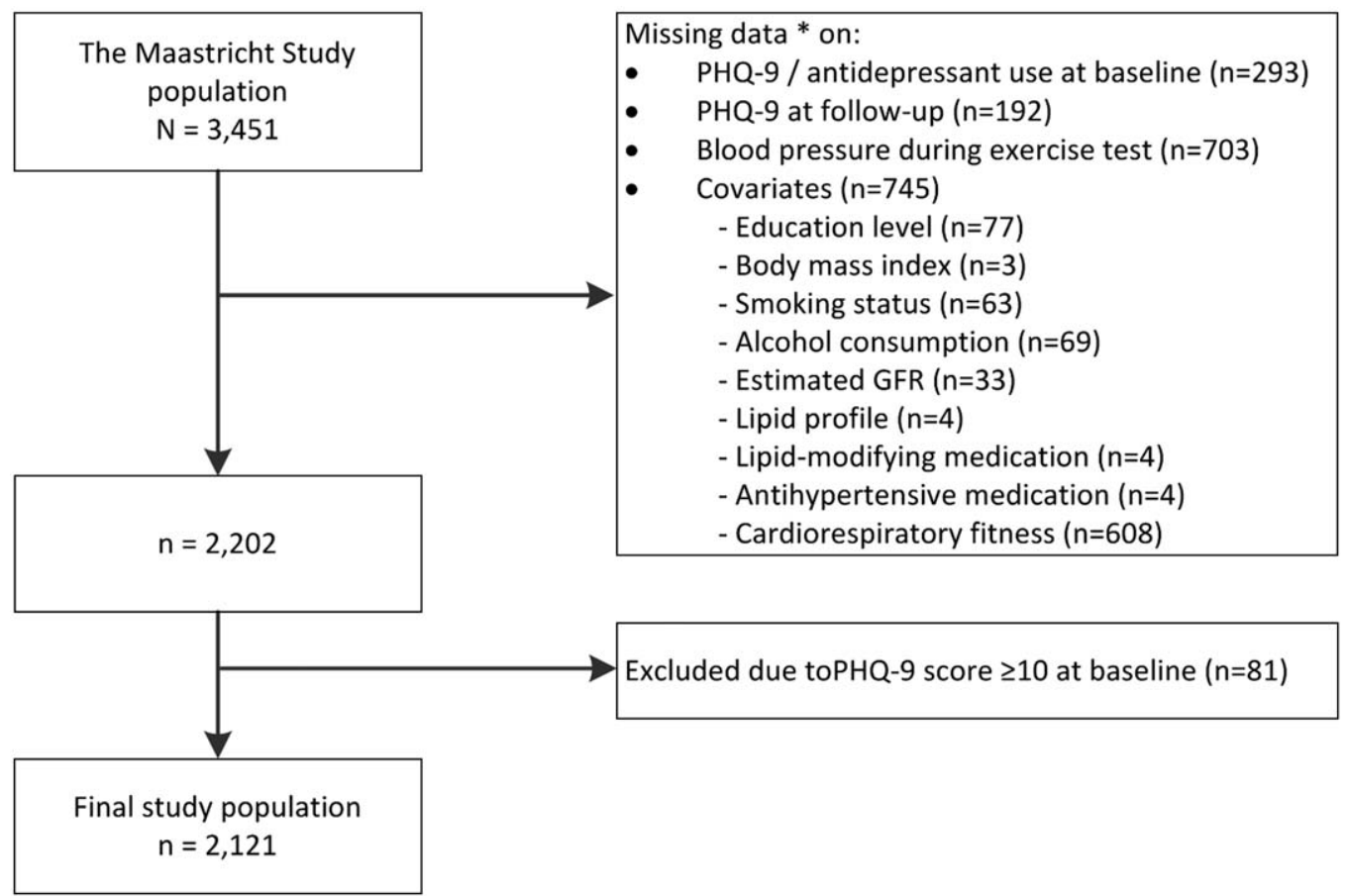

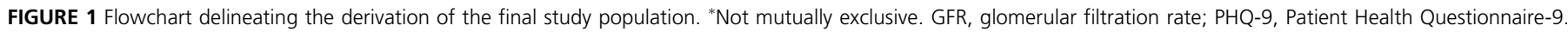


minute and SBP at 4 min after exercise); fourth, we used the continuous PHQ-9 scores as the outcome instead of PHQ-9 at least 10. For this analysis, we used generalized estimating equations for the negative binominal family and a log link function with an exchangeable correlation structure and robust standard errors. We used the interaction term exercise SBP $\times$ follow-up time, where a statistically significant interaction term indicates that a higher exercise SBP is associated with a different development of PHQ-9 scores over time; fifth, we additionally adjusted the main analysis for moderate-to-vigorous physical activity, carotid-to-femoral pulse wave velocity, HR at 4 min after exercise and markers of low-grade inflammation and endothelial dysfunction. We also adjusted for baseline socioeconomic status assessed by occupational status and income level (instead of education level), and for mean 24-h SBP instead of SBP at rest. We did not adjust for these factors in the main analyses, because they were either missing in a relatively large number of individuals (missing for physical activity, $n=118$; occupational status, $n=325$; for income, $n=390$; for 24 -h SBP, $n=216$ ) or due to potential overadjustment bias, that is, arterial stiffness, vagal tone, low-grade inflammation and endothelial dysfunction may lie on the potential causal pathway of exercise SBP to depression; sixth, we excluded individuals with prior cardiovascular disease to limit the risk of overadjustment bias; seventh, to limit the effects of prior depression, we excluded individuals with a history of a lifetime depression, as assessed by the Mini-International Neuropsychiatric Interview, and those who used antidepressant medication at baseline; eighth, we additionally analyzed baseline characteristics according to tertiles of exercise SBP and associated tertiles of exercise SBP (with the lowest tertile as reference) with incident clinically relevant depressive symptoms; and ninth, we repeated the analyses after multiple imputation of the missing potential confounders (fully conditional specification method with $n=10$ datasets).

All analyses were done with IBM SPSS software version 25.0 for Windows (IBM Corp., Somers, New York, USA). A two-sided $P$ value of less than 0.05 was considered statistically significant for all analyses.

\section{RESULTS}

Of the 2121 participants, 175 (8.3\%) had incident clinically relevant depressive symptoms after a mean follow-up of 3.9 (SD 1.0) years. Individuals with incident clinically relevant depressive symptoms as compared with those without more often had no partner, had received lower education, had a lower occupational status, more often had diabetes, had a worse cardiovascular risk profile and had higher exercise SBP values (Table 1 and Supplemental Table S2, http://links.lww.com/HJH/B460). The baseline characteristics according to tertiles of exercise SBP are shown in the Supplemental Table S3, http://links.lww.com/HJH/B460.

Figure $2 \mathrm{a}$, shows the mean PHQ-9 scores over time according to median values of the exercise SBP composite score. Table 2 shows the results of the Cox regression analysis. A 1 SD higher exercise SBP composite score was associated with a higher incidence of clinically relevant depressive symptoms [hazard ratio 1.27 (95\% confidence interval: 1.04-1.54); model 5].

Interaction analyses with sex showed that the association between the exercise SBP composite score and incident clinically relevant depressive symptoms was stronger in men compared with women $(P$ values for interaction 0.043, Supplemental Table S4, http://links.lww.com/HJH/ B460). No interactions were found for glucose metabolism status and age $(P$ values for interactions $>0.10)$.

\section{Additional analyses}

Resting office SBP, 24-h SBP and the exercise DBP composite score were not associated with incident clinically relevant depressive symptoms (Supplemental Tables S5 and S6, http://links.lww.com/HJH/B460). Of the individual exercise SBP variables, higher SBP at peak exercise and higher SBP change per minute were associated with a higher incidence of clinically relevant depressive symptoms (Fig. 3 and Supplemental Table S7, http://links.lww.com/ $\mathrm{HJH} / \mathrm{B} 460)$.

Analyses with continuous PHQ-9 scores showed that an exercise SBP composite score was associated with a higher increase of depressive symptoms over time $[P$ value for interaction $<0.001$; rate ratio $1.029(1.014-1.045)$, Supplemental Table S8, http://links.lww.com/HJH/B460]. Results did not change when we additionally adjusted for moderate-to-vigorous physical activity, carotid-to-femoral pulse wave velocity, HR at $4 \mathrm{~min}$ after exercise, markers of lowgrade inflammation or endothelial dysfunction (Supplemental Table S9, http://links.lww.com/HJH/B460). In addition, results did not materially change when we adjusted for occupational status and income level instead of education level, or 24-h SBP instead of SBP at rest (Supplemental Table S9, http://links.lww.com/HJH/B460). Results were also similar when we excluded individuals with prior cardiovascular disease, those with a history of a lifetime depression, or those who used antidepressant medication at baseline (Supplemental Tables S10 and S11, http://links.lww.com/HJH/B460), or when we repeated the analyses after multiple imputation (Supplemental Table S12, http:// links.lww.com/HJH/B460). When we analyzed the results according to tertiles of exercise SBP, risk of incident clinically relevant depressive symptoms increased from the lowest to the highest tertile of all exercise SBP (Supplemental Table S13, http://links.lww.com/HJH/B460).

\section{DISGUSSION}

In the present large population-based cohort study, a higher exercise SBP response was associated with a higher incidence of clinically relevant depressive symptoms, after accounting for socioeconomic factors, lifestyle, resting SBP, cardiovascular risk factors and cardiorespiratory fitness. To the best of our knowledge, this is the first longitudinal study to report that a higher SBP response during exercise may be a risk factor for incident depressive symptoms.

Only one previous study evaluated the association between exercise BP and depression, and did not find an association between exercise BP and depression [39]. However, that study had a cross-sectional design and used only postexercise $\mathrm{BP}$ as a measure of exercise $\mathrm{BP}$. 
TABLE 1. Baseline characteristics of study population

\begin{tabular}{|c|c|c|c|c|}
\hline Characteristic & $\begin{array}{c}\text { Total study } \\
\text { population, } \\
n=2121\end{array}$ & $\begin{array}{l}\text { No incident clinically } \\
\text { relevant depressive } \\
\text { symptoms, } n=1946 ; 91.7 \%\end{array}$ & $\begin{array}{l}\text { Incident clinically } \\
\text { relevant depressive } \\
\text { symptoms, } n=175 ; 8.3 \%\end{array}$ & $P$ value \\
\hline \multicolumn{5}{|l|}{ Demographics } \\
\hline Age (years) & $59.5 \pm 8.1$ & $59.6 \pm 8.1$ & $59.0 \pm 8.1$ & 0.02 \\
\hline Men & $1069(50.4 \%)$ & $981(50.4 \%)$ & $88(50.3 \%)$ & 0.68 \\
\hline Partner & $1763(83.1 \%)$ & $1628(83.7 \%)$ & $135(77.1 \%)$ & $<0.01$ \\
\hline Education level & & & & $<0.01$ \\
\hline Low & $627(29.6 \%)$ & $561(28.8 \%)$ & $66(37.7 \%)$ & \\
\hline Intermediate & $613(28.9 \%)$ & $559(28.7 \%)$ & $54(30.9 \%)$ & \\
\hline High & $881(41.5 \%)$ & $826(42.4 \%)$ & $55(31.4 \%)$ & \\
\hline \multicolumn{5}{|l|}{ Lifestyle variables } \\
\hline Smoking behavior & & & & $<0.01$ \\
\hline Never & $788(37.2 \%)$ & $738(38.4 \%)$ & $50(28.6 \%)$ & \\
\hline Former & $1091(51.4 \%)$ & $1004(51.6 \%)$ & $87(49.7 \%)$ & \\
\hline Current & $242(11.4 \%)$ & $204(10.5 \%)$ & $38(21.7 \%)$ & \\
\hline Alcohol consumption & & & & $<0.01$ \\
\hline None & $338(15.9 \%)$ & $297(15.3 \%)$ & $41(23.4 \%)$ & \\
\hline Low & $1203(56.7 \%)$ & $1106(56.8 \%)$ & $97(55.4 \%)$ & \\
\hline High & $580(27.3 \%)$ & $543(27.9 \%)$ & $37(21.1 \%)$ & \\
\hline \multicolumn{5}{|l|}{ Clinical characteristics } \\
\hline Glucose metabolism status & & & & $<0.01$ \\
\hline Normal glucose metabolism & $1296(61.1 \%)$ & $1212(62.3 \%)$ & $84(48.0 \%)$ & \\
\hline Prediabetes & $319(15.0 \%)$ & $293(15.1 \%)$ & $26(14.9 \%)$ & \\
\hline Type 2 diabetes & $484(22.8 \%)$ & $424(21.8 \%)$ & $60(34.3 \%)$ & \\
\hline Type 1 diabetes/Other types of diabetes & $22(1.1 \%)$ & $17(0.9 \%)$ & $5(2.9 \%)$ & \\
\hline BMI $\left(\mathrm{kg} / \mathrm{m}^{2}\right)$ & $26.6 \pm 4.1$ & $26.5 \pm 4.1$ & $27.5 \pm 4.6$ & $<0.01$ \\
\hline History of cardiovascular disease & $276(13.0 \%)$ & $252(12.9 \%)$ & $24(13.7 \%)$ & 0.41 \\
\hline Estimated glomerular filtration rate $\left(\mathrm{ml} / \mathrm{min} / 1.73 \mathrm{~m}^{2}\right)$ & $88.8 \pm 14.0$ & $88.8 \pm 13.8$ & $88.8 \pm 16.9$ & $<0.01$ \\
\hline Total-to-HDL cholesterol ratio & $3.6 \pm 1.1$ & $3.6 \pm 1.1$ & $3.8 \pm 1.3$ & 0.56 \\
\hline Use of lipid-modifying medication & $693(32.7 \%)$ & $629(32.3 \%)$ & $64(36.6 \%)$ & $<0.01$ \\
\hline Use of antihypertensive medication & $746(35.2 \%)$ & $674(34.6 \%)$ & $72(41.1 \%)$ & $<0.01$ \\
\hline ACE-inhibitor & $217(10.2 \%)$ & $201(10.3 \%)$ & $16(9.1 \%)$ & 0.07 \\
\hline Angiotensin II receptor blocker & $348(16.4 \%)$ & $309(15.9 \%)$ & $39(22.3 \%)$ & $<0.01$ \\
\hline$\beta$-Blocker & $303(14.3 \%)$ & $277(14.2 \%)$ & $26(14.9 \%)$ & $<0.01$ \\
\hline Calcium channel blocker & $164(7.7 \%)$ & $150(7.7 \%)$ & $14(8.0 \%)$ & $<0.01$ \\
\hline Diuretic & $306(14.4 \%)$ & $277(14.2 \%)$ & $29(16.6 \%)$ & $<0.01$ \\
\hline Office SBP (mmHg) & $134.3 \pm 17.7$ & $134.2 \pm 17.6$ & $135.8 \pm 18.2$ & 0.58 \\
\hline Office DBP $(\mathrm{mmHg})$ & $76.1 \pm 9.7$ & $76.0 \pm 9.6$ & $77.2 \pm 11.2$ & $<0.01$ \\
\hline Cardiorespiratory fitness (W/kg) & $2.18 \pm 0.58$ & $2.20 \pm 0.57$ & $1.97 \pm 0.56$ & 0.21 \\
\hline \multicolumn{5}{|l|}{ Submaximal exercise test blood pressures } \\
\hline Resting SBP (mmHg) & $132.6 \pm 18.4$ & $132.5 \pm 18.4$ & $133.7 \pm 18.6$ & 0.21 \\
\hline Exercise SBP composite score, SD & $0.00 \pm 1.00$ & $-0.02 \pm 1.00$ & $0.22 \pm 1.02$ & $<0.01$ \\
\hline SBP at moderate workload $(\mathrm{mmHg})$ & $152.6 \pm 22.4$ & $152.3 \pm 22.3$ & $156.0 \pm 18.6$ & 0.20 \\
\hline SBP at peak exercise $(\mathrm{mmHg})$ & $176.9 \pm 27.0$ & $176.6 \pm 27.0$ & $180.1 \pm 26.8$ & 0.73 \\
\hline SBP change per $\min (\mathrm{mmHg} / \mathrm{min})$ & $5.4 \pm 2.7$ & $5.3 \pm 2.6$ & $6.1 \pm 2.9$ & $<0.01$ \\
\hline SBP at 4 min after exercise $(\mathrm{mmHg})$ & $143.8 \pm 21.7$ & $143.5 \pm 21.7$ & $147.2 \pm 21.2$ & 0.07 \\
\hline \multicolumn{5}{|l|}{ Depressive symptoms } \\
\hline PHQ-9 score & $2[0-3]$ & $1[0-3]$ & $4[2-7]$ & $<0.01$ \\
\hline
\end{tabular}

Data are presented as mean \pm SD, median [interquartile range] or $n$ (\%). ACE, angiotensin-converting enzyme; PHQ-9, Patient Health Questionnaire-9.

Several mechanisms may explain the association between an exaggerated exercise SBP and incident depressive symptoms. First, exaggerated exercise SBP is linked to a higher pulsatile load on the brain [40] which may lead to depressive symptoms [7]. An increased pulsatile load can penetrate into the cerebral circulation and may directly cause cerebral ischemia and hemorrhage [19]. In addition, the increased load may induce a vascular remodeling response, characterized by wall thickening, diameter widening and rarefaction of small cerebral arteries, which, in turn, may lead to chronic ischemia [30,41,42]. Also, the increased pulsatile load may lead to higher arterial wall shear stress and development of rupture-prone atherosclerotic plaques [43]. If cerebral ischemia occurs in the frontal- subcortical cerebral circuits involved in mood regulation, this may lead to the development of depressive symptoms [7]. Accordingly, an exaggerated exercise SBP has been associated with a smaller total brain volume [23] and higher white matter hyperintensity volume [24] in later life, which are features of cerebral small vessel disease, and such alterations may lead to depressive symptoms [14]. Second, other biological factors may underlie both an exaggerated exercise SBP and depressive symptoms, including aortic stiffening [12,44,45], high sympathetic tone [46,47], lowgrade inflammation [48,49], endothelial dysfunction $[6,50]$ and increased activation of the renin-angiotensin-aldosterone system [51,52]. However, results did not materially change when we additionally adjusted for carotid-to- 
(a) Exercise SBP composite score

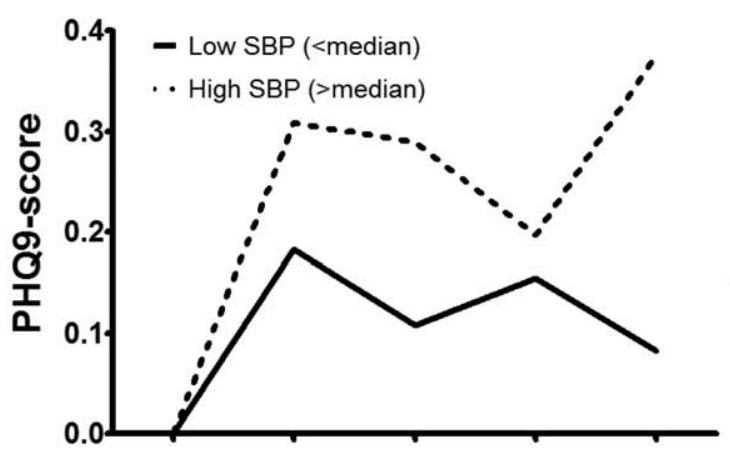

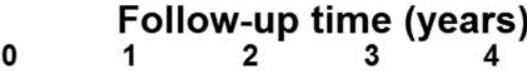

(b)

SBP at moderate workload

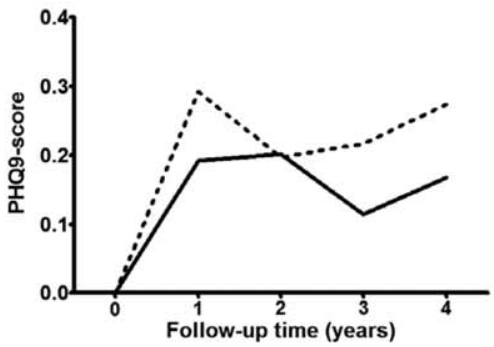

(d) SBP change per minute

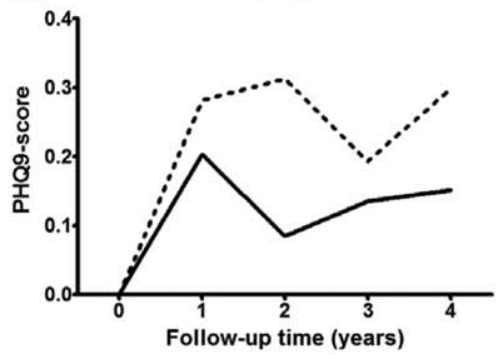

(c) SBP at peak exercise

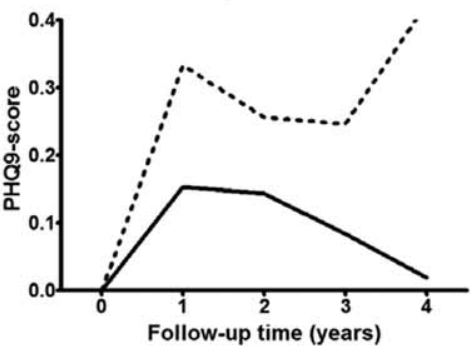

(e) SBP 4 minutes after exercise

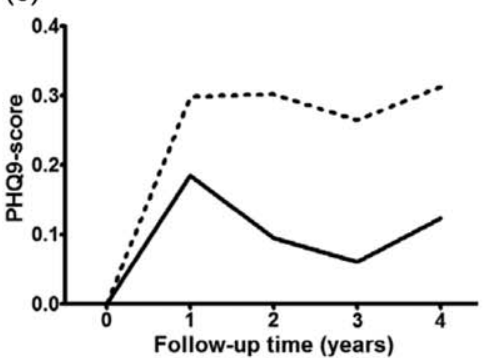

FIGURE 2 Mean Patient Health Questionnaire-9 score during follow-up according median values of (a) the exercise SBP composite score; (b) SBP at moderate workload; (c) SBP at peak exercise; (d) SBP change per minute; (e) SBP 4 min after exercise.

TABLE 2. Associations between exercise SBP and incidence of clinically relevant depressive symptoms (Patient Health Questionnaire-9

\begin{tabular}{|c|c|c|c|c|c|c|c|c|c|c|}
\hline & \multicolumn{2}{|c|}{ Model 1} & \multicolumn{2}{|c|}{ Model 2} & \multicolumn{2}{|c|}{ Model 3} & \multicolumn{2}{|c|}{ Model 4} & \multicolumn{2}{|c|}{ Model 5} \\
\hline & HR & $(95 \% \mathrm{Cl})$ & HR & $(95 \% \mathrm{Cl})$ & HR & $(95 \% \mathrm{Cl})$ & HR & $(95 \% \mathrm{Cl})$ & HR & $(95 \% \mathrm{Cl})$ \\
\hline
\end{tabular}

HRs represent risk on incident clinically relevant depressive symptoms (PHQ-9 $>10$ ) for every 1 SD increase in exercise SBP variable. Bold denotes $P$ value less than 0.05 . Model 1 : age, sex, glucose metabolism status, education level; model 2: model 1 + partner status, alcohol consumption, smoking status, BMI, prior cardiovascular disease; model 3: model

2 + estimated glomerular filtration rate, total-to-HDL cholesterol ratio, resting SBP, lipid-modifying and antihypertensive medication (with the individual antihypertensive classes

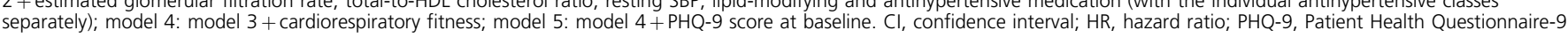

femoral pulse wave velocity (a marker of aortic stiffness [53]), HR at 4 min after exercise (a marker for vagal tone [54]) or markers of low-grade inflammation or endothelial dysfunction. In this study, no data were available on activation of the renin-angiotensin-aldosterone system and this requires further study. Third, the association between exercise SBP and depressive symptoms may be confounded by factors such as low socioeconomic status, sedentary behavior, concomitant cardiovascular disease and a history of a lifetime depression or use of antidepressant medication at

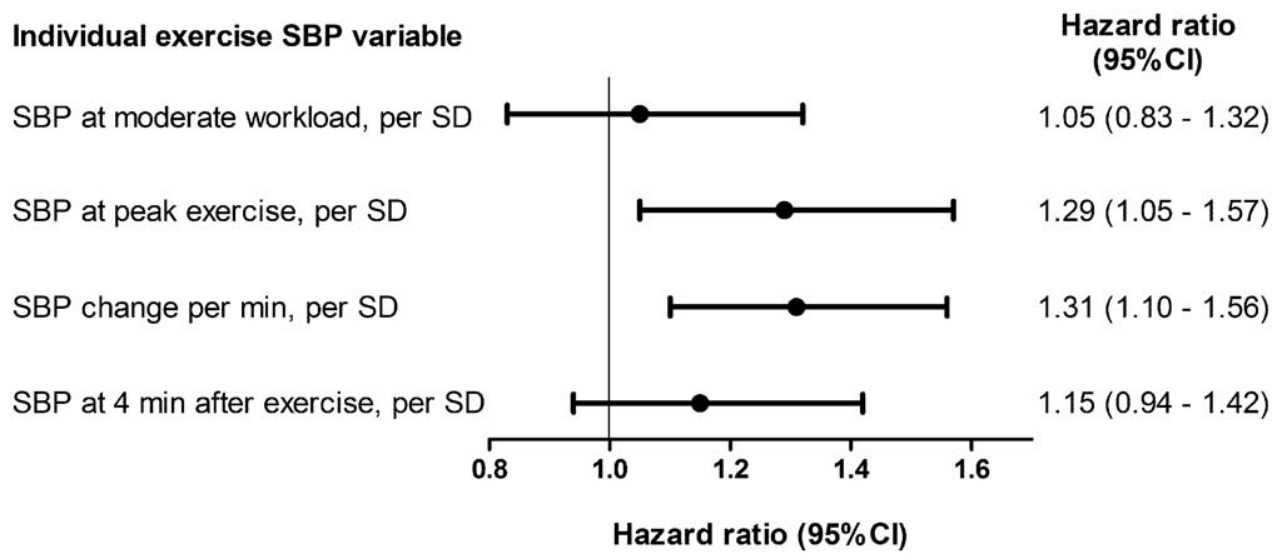

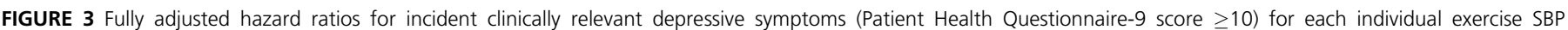

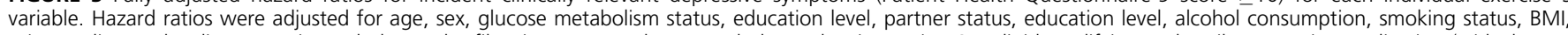
prior cardiovascular disease; estimated glomerular filtration rate, total-to-HDL cholesterol ratio, resting SBP, lipid-modifying and antihypertensive medication (with the individual antihypertensive classes separately), cardiorespiratory fitness and baseline Patient Health Questionnaire- 9 scores. $\mathrm{Cl}$, confidence interval; min, minute. 
baseline. However, associations remained similar when we adjusted for occupational status, income, education level and physical activity, and when we excluded individuals with prior cardiovascular disease, prior history of a lifetime depression or those who used antidepressant medication at baseline. Nevertheless, we cannot exclude the possibility of residual confounding.

We observed that the association between exercise SBP and development of depressive symptoms was stronger in men than in women. Sex hormones such as estrogen may have a protective effect on the vasculature [55,56], which may have reduced the impact of exercise SBP on the brain and subsequent depressive symptoms in women. Further studies are needed to investigate this issue.

We did not find any association between mean resting office SBP and 24-h SBP and incident depressive symptoms, which is in accordance with most previous studies [16-18]. An exaggerated exercise SBP may reflect the pulsatile aspect of $\mathrm{BP}$ more accurately than mean $\mathrm{BP}$, and it has been suggested that this pulsatile aspect of increased BP may be particularly harmful to the brain [19]. In addition, we did not find an association between exercise DBP and incident depressive symptoms. An exaggerated exercise DBP may also be less strongly related to an increased pulsatile load than an exaggerated exercise SBP response [6]. In addition, exercise DBP may be a more important risk factor among younger individuals [57]. The Framingham Study found that an exaggerated exercise DBP is most strongly associated with incident cardiovascular events in younger individuals ( $<45$ years) [57], whereas the average age of our study population was 60 years. We therefore cannot exclude the possibility of an association between exercise DBP response and depressive symptoms in younger individuals, and this issue requires further study.

The results of the current study may be clinically relevant, as they suggest that an exaggerated exercise SBP not only predicts future development of cardiovascular disease, but should also be recognized as implying a higher risk of depression. Importantly, an exaggerated exercise SBP is a modifiable risk factor and may be treated with lifestyle intervention (e.g. exercise training [58,59]) and the use of $\beta$-blockers $[60,61]$. Future studies are needed to evaluate whether treatment of exaggerated exercise SBP can reduce depressive symptoms.

Strengths of our study are its population-based and longitudinal design and the extensive characterization of the participants, which allowed us to adjust for a large number of potential confounders.

Our study also had several limitations. First, depressive symptoms were assessed by a self-reported questionnaire, and no information was available on incident clinical depression. This may limit the interpretation of our findings, and further study is needed to evaluate whether high exercise SBP is also associated with risk of clinical depression. However, the PHQ-9 (with a cutoff score of 10) has a high sensitivity and specificity (88 and 85\%, respectively) compared with a structured interview for the diagnosis of a depression [62]. Moreover, depressive symptoms without the diagnosis of clinical depression have been associated with an increased risk of morbidity and mortality [63,64].
Also, the prevalence of depressive symptoms is higher than the prevalence of clinical depression, particularly in older individuals [1]. Second, we did not have information about any new use of antidepressant medication at follow-up. This may have led to an underestimation of the presence of depressive symptoms at follow-up, and, therefore, an underestimation of the association between exercise SBP and depression. Third, our study population consisted of older individuals of white ethnicity, which limits the generalizability of our results.

In conclusion, a higher exercise SBP response is associated with incident clinically relevant depressive symptoms. This suggests that an exaggerated exercise SBP response may be a modifiable risk factor for late-life depression. If confirmed in other longitudinal studies, intervention studies are needed to determine whether treatment of an exaggerated exercise SBP can prevent depressive symptoms.

\section{AGKNOWLEDGEMENTS}

Previous presentations: Parts of this study were presented in abstract form at the ARTERY19 Conference, Budapest, Hungary, 10-12 October 2019.

The study was supported by the European Regional Development Fund via OP-Zuid, the Province of Limburg, the Dutch Ministry of Economic Affairs (grant 310.041), Stichting De Weijerhorst (Maastricht, the Netherlands), the Pearl String Initiative Diabetes (Amsterdam, the Netherlands), CARIM School for Cardiovascular Diseases (Maastricht, the Netherlands), Stichting Annadal (Maastricht, the Netherlands), Health Foundation Limburg (Maastricht, the Netherlands) and by unrestricted grants from Janssen-Cilag B.V. (Tilburg, the Netherlands), Novo Nordisk Farma B.V. (Alphen aan den Rijn, the Netherlands) and Sanofi-Aventis Netherlands B.V. (Gouda, the Netherlands). T.T.v.S. is supported by a VENI research grant (916.19.074) from The Netherlands Organization for Scientific Research (NWO) and The Netherlands Organization for Health Research and Development (ZonMw), and by a Dutch Heart Foundation research grant (2018T025). None of the funders had a role in the design and conduct of the study; collection, management, analysis and interpretation of the data; preparation, review or approval of the article; and decision to submit the article for publication.

\section{Conflicts of interest}

All authors report no conflicts of interest.

\section{REFERENGES}

1. World Health Organization. Depression and other common mental disorders: global health estimates. Geneva: World Health Organization; 2017.

2. Lichtman JH, Froelicher ES, Blumenthal JA, Carney RM, Doering LV, Frasure-Smith N, et al. Depression as a risk factor for poor prognosis among patients with acute coronary syndrome: systematic review and recommendations: a scientific statement from the American Heart Association. Circulation 2014; 129:1350-1369.

3. Carney RM, Freedland KE. Depression and coronary heart disease. Nat Rev Cardiol 2017; 14:145-155.

4. Valkanova V, Ebmeier KP. Vascular risk factors and depression in later life: a systematic review and meta-analysis. Biol Psychiatry 2013; 73:406-413. 
5. Taylor WD, Aizenstein HJ, Alexopoulos GS. The vascular depression hypothesis: mechanisms linking vascular disease with depression. Mol Psychiatry 2013; 18:963-974.

6. Thanassoulis G, Lyass A, Benjamin EJ, Larson MG, Vita JA, Levy D, et al. Relations of exercise blood pressure response to cardiovascular risk factors and vascular function in the Framingham Heart Study. Circulation 2012; 125:2836-2843.

7. Alexopoulos GS, Meyers BS, Young RC, Campbell S, Silbersweig D, Charlson M. 'Vascular depression' hypothesis. Arch Gen Psychiatry 1997; 54:915-922.

8. Chen S, Zhang Q, Dai G, Hu J, Zhu C, Su L, Wu X. Association of depression with prediabetes, undiagnosed diabetes, and previously diagnosed diabetes: a meta-analysis. Endocrine 2016; 53:35-46.

9. Schuch FB, Vancampfort D, Firth J, Rosenbaum S, Ward PB, Silva ES, et al. Physical activity and incident depression: a meta-analysis of prospective cohort studies. Am J Psychiatry 2018; 175:631-648.

10. Molendijk M, Molero P, Ortuno Sanchez-Pedreno F, Van der Does W, Angel Martinez-Gonzalez M. Diet quality and depression risk: a systematic review and dose-response meta-analysis of prospective studies. J Affect Disord 2018; 226:346-354.

11. Palmer S, Vecchio M, Craig JC, Tonelli M, Johnson DW, Nicolucci A, et al. Prevalence of depression in chronic kidney disease: systematic review and meta-analysis of observational studies. Kidney Int 2013; 84:179-191.

12. van Sloten TT, Boutouyrie P, Tafflet M, Offredo L, Thomas F, Guibout C, et al. Carotid artery stiffness and incident depressive symptoms: the Paris Prospective Study III. Biol Psychiatry 2019; 85:498-505.

13. van Agtmaal MJM, Houben A, Pouwer F, Stehouwer CDA, Schram MT. Association of microvascular dysfunction with late-life depression: a systematic review and meta-analysis. JAMA Psychiatry 2017; 74:729739 .

14. Rensma SP, van Sloten TT, Launer LJ, Stehouwer CDA. Cerebral small vessel disease and risk of incident stroke, dementia and depression, and all-cause mortality: a systematic review and meta-analysis. Neurosci Biobehav Rev 2018; 90:164-173.

15. Zimmerman JA, Mast BT, Miles T, Markides KS. Vascular risk and depression in the Hispanic Established Population for the Epidemiologic Study of the Elderly (EPESE). Int J Geriatr Psychiatry 2009; 24:409-416.

16. Kim JM, Stewart R, Kim SW, Yang SJ, Shin IS, Yoon JS. Vascular risk factors and incident late-life depression in a Korean population. $\mathrm{Br} \mathrm{I}$ Psychiatry 2006; 189:26-30.

17. Luijendijk HJ, Stricker BH, Hofman A, Witteman JC, Tiemeier H. Cerebrovascular risk factors and incident depression in communitydwelling elderly. Acta Psychiatr Scand 2008; 118:139-148.

18. Mast BT, Miles T, Penninx BW, Yaffe K, Rosano C, Satterfield S, et al. Vascular disease and future risk of depressive symptomatology in older adults: findings from the Health, Aging, and Body Composition study. Biol Psychiatry 2008; 64:320-326.

19. Mitchell GF. Effects of central arterial aging on the structure and function of the peripheral vasculature: implications for end-organ damage. J Appl Physiol 2008; 105:1652-1660.

20. Schultz MG, Sharman JE. Exercise hypertension. Pulse (Basel) 2014; $1: 161-176$.

21. Kurl S, Laukkanen JA, Rauramaa R, Lakka TA, Sivenius J, Salonen JT. Systolic blood pressure response to exercise stress test and risk of stroke. Stroke 2001; 32:2036-2041.

22. Hutcheon JA, Chiolero A, Hanley JA. Random measurement error and regression dilution bias. BMJ 2010; 340:c2289.

23. Spartano NL, Himali JJ, Beiser AS, Lewis GD, DeCarli C, Vasan RS, Seshadri S. Midlife exercise blood pressure, heart rate, and fitness relate to brain volume 2 decades later. Neurology 2016; 86:1313-1319.

24. Williamson W, Lewandowski AJ, Forkert ND, Griffanti L, Okell TW, Betts J, et al. Association of cardiovascular risk factors with MRI indices of cerebrovascular structure and function and white matter hyperintensities in young adults. JAMA 2018; 320:665-673.

25. Schram MT, Sep SJ, van der Kallen CJ, Dagnelie PC, Koster A, Schaper $\mathrm{N}$, et al. The Maastricht Study: an extensive phenotyping study on determinants of type 2 diabetes, its complications and its comorbidities. Eur J Epidemiol 2014; 29:439-451.

26. Van Der Velde J, Koster A, Van Der Berg J, Sep SJS, Van Der Kallen C, Dagnelie PC, et al. Sedentary behavior, physical activity, and fitness the Maastricht Study. Med Sci Sports Exerc 2017; 49:1583-1591.
27. Mason RE, Likar I. A new system of multiple-lead exercise electrocardiography. Am Heart J 1966; 71:196-205.

28. Schultz MG, Otahal P, Cleland VJ, Blizzard L, Marwick TH, Sharman JE. Exercise-induced hypertension, cardiovascular events, and mortality in patients undergoing exercise stress testing: a systematic review and meta-analysis. Am J Hypertens 2013; 26:357-366.

29. Kroenke K, Spitzer RL, Williams JB. The PHQ-9: validity of a brief depression severity measure. J Gen Intern Med 2001; 16:606-613.

30. van Sloten TT, Schram MT, Adriaanse MC, Dekker JM, Nijpels G, Teerlink T, et al. Endothelial dysfunction is associated with a greater depressive symptom score in a general elderly population: the Hoorn Study. Psychol Med 2014; 44:1403-1416.

31. O'Brien PC. Procedures for comparing samples with multiple endpoints. Biometrics 1984; 40:1079-1087.

32. Hare DL, Toukhsati SR, Johansson P, Jaarsma T. Depression and cardiovascular disease: a clinical review. Eur Heart J 2014; 35:13651372.

33. Nichols GA, Moler EJ. Cardiovascular disease, heart failure, chronic kidney disease and depression independently increase the risk of incident diabetes. Diabetologia 2011; 54:523-526.

34. Martens RJH, Kooman JP, Stehouwer CDA, Dagnelie PC, van der Kallen $\mathrm{CJH}$, Kroon AA, et al. Albuminuria is associated with a higher prevalence of depression in a population-based cohort study: the Maastricht Study. Nephrol Dial Transplant 2018; 33:128-138.

35. Willis BL, Leonard D, Barlow CE, Martin SB, DeFina LF, Trivedi MH. Association of midlife cardiorespiratory fitness with incident depression and cardiovascular death after depression in later life. JAMA Psychiatry 2018; 75:911-917.

36. Schiebinger L, Leopold SS, Miller VM. Editorial policies for sex and gender analysis. Lancet 2016; 388:2841-2842.

37. Onete V, Henry RM, Sep SJS, Koster A, van der Kallen CJ, Dagnelie PC, et al. Arterial stiffness is associated with depression in middle-aged men - the Maastricht Study. J Psychiatry Neurosci 2017; 42:160246.

38. Climie RE, Van Sloten TT, Bruno RM, Taddei S, Empana JP, Stehouwer CDA, et al. Macrovasculature and microvasculature at the crossroads between type 2 diabetes mellitus and hypertension. Hypertension 2019; 73:1138-1149.

39. Gordon JL, Ditto B, Lavoie KL, Pelletier R, Campbell TS, Arsenault A, Bacon SL. The effect of major depression on postexercise cardiovascular recovery. Psychophysiology 2011; 48:1605-1610.

40. Mitchell GF, van Buchem MA, Sigurdsson S, Gotal JD, Jonsdottir MK, Kjartansson $\mathrm{O}$, et al. Arterial stiffness, pressure and flow pulsatility and brain structure and function: the Age, Gene/Environment Susceptibility - Reykjavik study. Brain 2011; 134 (Pt 11):3398-3407.

41. Irace C, Gnasso A, Cirillo F, Leonardo G, Ciamei M, Crivaro A, et al. Arterial remodeling of the common carotid artery after aortic valve replacement in patients with aortic stenosis. Stroke 2002; 33:24462450.

42. Johansson BB. Hypertension mechanisms causing stroke. Clin Exp Pharmacol Physiol 1999; 26:563-565.

43. Fukumoto Y, Hiro T, Fujii T, Hashimoto G, Fujimura T, Yamada J, et al. Localized elevation of shear stress is related to coronary plaque rupture: a 3-dimensional intravascular ultrasound study with in-vivo color mapping of shear stress distribution. I Am Coll Cardiol 2008; $51: 645-650$

44. Sung J, Choi SH, Choi YH, Kim DK, Park WH. The relationship between arterial stiffness and increase in blood pressure during exercise in normotensive persons. J Hypertens 2012; 30:587-591.

45. Tsioufis C, Dimitriadis K, Thomopoulos C, Tsiachris D, Selima M, Stefanadi E, et al. Exercise blood pressure response, albuminuria, and arterial stiffness in hypertension. Am J Med 2008; 121:894-902.

46. Weston KS, Sacre JW, Jellis CL, Coombes JS. Contribution of autonomic dysfunction to abnormal exercise blood pressure in type 2 diabetes mellitus. J Sci Med Sport 2013; 16:8-12.

47. Kemp AH, Quintana DS, Gray MA, Felmingham KL, Brown K, Gatt JM. Impact of depression and antidepressant treatment on heart rate variability: a review and meta-analysis. Biol Psychiatry 2010; 67:1067-1074.

48. Hamer M, Steptoe A. Vascular inflammation and blood pressure response to acute exercise. Eur J Appl Physiol 2012; 112:2375-2379.

49. Kiecolt-Glaser JK, Derry HM, Fagundes CP. Inflammation: depression fans the flames and feasts on the heat. Am J Psychiatry 2015; 172:10751091. 
50. Broadley AJ, Korszun A, Jones CJ, Frenneaux MP. Arterial endothelial function is impaired in treated depression. Heart 2002; 88:521-523.

51. Fallo F. Renin-angiotensin-aldosterone system and physical exercise. J Sports Med Phys Fitness 1993; 33:306-312.

52. Vian J, Pereira C, Chavarria V, Kohler C, Stubbs B, Quevedo J, et al. The renin-angiotensin system: a possible new target for depression. BMC Med 2017; 15:144.

53. Laurent S, Cockcroft J, Van Bortel L, Boutouyrie P, Giannattasio C, Hayoz D, et al. Expert consensus document on arterial stiffness: methodological issues and clinical applications. Eur Heart J 2006; 27:2588-2605.

54. Imai K, Sato H, Hori M, Kusuoka H, Ozaki H, Yokoyama H, et al. Vagally mediated heart rate recovery after exercise is accelerated in athletes but blunted in patients with chronic heart failure. J Am Coll Cardiol 1994; 24:1529-1535.

55. Vaidya D, Golden SH, Haq N, Heckbert SR, Liu K, Ouyang P. Association of sex hormones with carotid artery distensibility in men and postmenopausal women: multiethnic study of atherosclerosis. Hypertension 2015; 65:1020-1025.

56. Hodis HN, Mack WJ, Henderson VW, Shoupe D, Budoff MJ, HwangLevine $\mathrm{J}$, et al. Vascular effects of early versus late postmenopausal treatment with estradiol. $N$ Engl J Med 2016; 374:1221-1231.

57. Lewis GD, Gona P, Larson MG, Plehn JF, Benjamin EJ, O’Donnell CJ, et al. Exercise blood pressure and the risk of incident cardiovascular disease (from the Framingham Heart Study). Am J Cardiol 2008; 101:1614-1620.
58. Dimeo F, Pagonas N, Seibert F, Arndt R, Zidek W, Westhoff TH. Aerobic exercise reduces blood pressure in resistant hypertension. Hypertension 2012; 60:653-658.

59. Schultz MG, Hordern MD, Leano R, Coombes JS, Marwick TH, Sharman JE. Lifestyle change diminishes a hypertensive response to exercise in type 2 diabetes. Med Sci Sports Exerc 2011; 43:764-769.

60. Haasis R, Bethge H. Exercise blood pressure and heart rate reduction 24 and $3 \mathrm{~h}$ after drug intake in hypertensive patients following 4 weeks of treatment with bisoprolol and metoprolol: a randomized multicentre double-blind study (BISOMET). Eur Heart J 1987; 8 (Suppl M):103113.

61. Kokkinos P, Chrysohoou C, Panagiotakos D, Narayan P, Greenberg M, Singh S. Beta-blockade mitigates exercise blood pressure in hypertensive male patients. J Am Coll Cardiol 2006; 47:794-798.

62. Levis B, Benedetti A, Thombs BD, DEPRESsion Screening Data (DEPRESSD) Collaboration. Accuracy of Patient Health Questionnaire-9 (PHQ-9) for screening to detect major depression: individual participant data meta-analysis. BMJ 2019; 365:11476.

63. Ariyo AA, Haan M, Tangen CM, Rutledge JC, Cushman M, Dobs A, Furberg CD. Depressive symptoms and risks of coronary heart disease and mortality in elderly Americans. Cardiovascular Health Study Collaborative Research Group. Circulation 2000; 102:17731779.

64. Barefoot JC, Schroll M. Symptoms of depression, acute myocardial infarction, and total mortality in a community sample. Circulation 1996; 93:1976-1980. 